\title{
Which is better for gastric cancer patients, perioperative or adjuvant chemotherapy: a meta-analysis
}

Jun-hua Zhao ${ }^{\dagger}$, Peng Gao ${ }^{\dagger}$, Yong-xi Song, Jing-xu Sun, Xiao-wan Chen, Bin Ma, Yu-chong Yang and Zhen-ning Wang*

\begin{abstract}
Background: The preferred chemotherapy method for gastric cancer continues to be matter of debate. We performed a meta-analysis to comparing prognosis and safety between perioperative chemotherapy and adjuvant chemotherapy to identify the better chemotherapy option for gastric cancer.

Methods: We searched the PubMed, EMBASE, Cochrane Library, and Ovid databases for eligible studies until February 2016. The main endpoints were prognostic value (hazard ratio [HR] for overall survival [OS] and 1-, 2-, 3-, and 5-year survival rate), response rate of chemotherapy, radical resection rate, post-operative complication rate, and adverse effects of chemotherapy.

Results: Five randomized controlled trials and six clinical controlled trials involving 1,240 patients were eligible for analysis. Compared with the adjuvant chemotherapy group, the perioperative chemotherapy group had significantly better prognosis ( $\mathrm{HR}, 0.74 ; 95 \% \mathrm{Cl}, 0.61$ to $0.89 ; P<0.01$ ). The difference between the two groups remained significant in the studies that used combination chemotherapy as the neoadjuvant chemotherapy regimen ( $\mathrm{HR}, 0.59 ; 95 \% \mathrm{Cl}, 0.46$ to $0.76 ; P<0.01)$ but were not significant in the studies that used fluoropyrimidine monotherapy $(\mathrm{HR}, 0.93 ; 95 \% \mathrm{Cl}, 0.56$ to $1.55 ; P=0.84)$. Furthermore, the two groups showed no significant differences in the post-operative complication rates (relative risk, $0.98 ; 95 \% \mathrm{Cl}, 0.63$ to $1.51 ; P=0.91$ ) or adverse effects of chemotherapy ( $P>0.05$ for all adverse effects).

Conclusion: Perioperative chemotherapy showed improved survival compared to adjuvant chemotherapy for gastric cancer. In addition, combination chemotherapy resulted in better survival compared to monotherapy in the neoadjuvant chemotherapy regimens.
\end{abstract}

Keywords: Gastric cancer, Perioperative chemotherapy, Adjuvant chemotherapy, Overall survival, Combination chemotherapy

Abbreviations: AC, Adjuvant Chemotherapy; CCTs, Clinical Controlled Trials; Cls, Confidence Intervals; CR, Complete Response; GC, Gastric Cancer; HR, Hazard Ratio; NAC, Neoadjuvant Chemotherapy; OS, Overall Survival; PC, Perioperative Chemotherapy; PR, Partial Response; RCTs, Randomized Controlled Trials; RR, Risk Ratio

\footnotetext{
* Correspondence: josieon826@sina.cn

${ }^{\dagger}$ Equal contributors

Department of Surgical Oncology and General Surgery, the First Hospital of

China Medical University, Shenyang 110001, People's Republic of China
} 


\section{Background}

Gastric cancer (GC) is the fourth most common cancer and the second leading cause of cancer-related deaths worldwide $[1,2]$. To date, surgery is the only curative treatment for GC. However, the results are still unsatisfactory, owing to the high rate of metastasis and relapse [1, 3].

Chemotherapy together with surgery has shown promising results. For instance, a randomized controlled trial conducted by Cunningham et al. [4] showed that perioperative chemotherapy (PC) could result in better survival than surgery alone. Similarly, Bang et al. [5] showed that adjuvant chemotherapy $(\mathrm{AC})$ could improve survival over surgery alone. However, the method of delivery of chemotherapy for GC is still a matter of debate. PC consists of preoperative (neoadjuvant) chemotherapy and postoperative chemotherapy, and is provided as standard of care in NCCN guideline for GC. At the same time, the application of $\mathrm{AC}$ is limited to situations where neoadjuvant therapy had not been given prior to surgery [6]. However chemotherapy given prior to surgery may reduce tumor burden and eradicate micrometastatic foci outside the surgical field [7, 8]. Several studies have emphasized the survival benefits of PC to the patients $[9,10]$. However, chemortherapy given prior to surgery can cause fibrosis and tissue edema, which may cause difficulties during surgery [11], causing adverse effects to the patients $[12,13]$. Therefore, we performed a meta-analysis to compare the prognostic value, side effects, and post-operative complications of PC and AC in patients with GC.

\section{Methods}

\section{Search strategy}

Studies were selected by searching major medical databases (PubMed, EMBASE, Cochrane Library, and Ovid) for all articles published until February 1, 2016. We used the following keywords: "neoadjuvant", "preoperative", "perioperative", "chemotherapy", "stomach neoplasm", "gastric cancer", and "gastrectomy" Then, we narrowed the search by browsing the abstracts, methods, and references of the articles retrieved.

\section{Inclusion and exclusion criteria}

The studies that met the following criteria were included: (i) publications that compared PC with AC in patients with GC undergoing surgery; (ii) the full text of the articles was available, with a clear description of the chemotherapy regimens used in the study; (iii) at least one of the outcome measures mentioned below was reported or could be calculated from the data provided. In cases of overlap between authors or institutions, only the higher-quality or more recent study was selected. Studies were excluded for the following reasons: (i) PC and $\mathrm{AC}$ were not compared in the patients with GC; (ii) post-operative chemotherapy was not applied in either the PC or AC groups; (iii) radiotherapy was part of treatment.

\section{Outcome measures, data extraction, and assessment of the risk of bias}

The primary outcomes were prognostic value (hazard ratio [HR] for overall survival [OS] and 1-, 2-, 3-, and 5 -year survival rate), response rate of chemotherapy (response rate: complete response [CR] or partial response [PR] after chemotherapy), radical resection rate; total post-operative complication rate (defined on the basis of the system for reporting complications established by the Memorial Sloan-Kettering Cancer Center [14]), and the adverse effects of chemotherapy. Two authors independently extracted data from full-text articles using a unified datasheet. Randomized controlled trials (RCTs) were evaluated using the Jadad Composite Scale (JCS), wherein high-quality trials should score $\geq 3$ of a maximum possible score of 5 . Controlled clinical trials (CCTs) were evaluated using the NewcastleOttawa Scale [15], wherein high-quality trials should score $\geq 7$ of a maximum possible score of 9 , and moderate-quality trials should score $\geq 5$. Disagreements were presented to a third author and resolved by discussions among the investigators.

\section{Statistical analysis}

This meta-analysis was conducted using RevMan software version 5.2 (Cochrane Collaboration). The risk ratio (RR) and HR were used to evaluate the prognostic effect. If the HR and its variance were not reported directly in the original study, these values were calculated using a software designed by Tierney et al. [16]. For $\mathrm{HR}$, we performed subgroup analysis based on available method, such as study design, NAC regimen, et al. In addition, the RR was used to analyze other discontinuous variables. Both ratios were reported with $95 \%$ confidence intervals (CIs). Heterogeneity was determined using the $\chi^{2}$ test or Cochran $\mathrm{Q}$ test. $\mathrm{I}^{2}$ was used to quantify heterogeneity. $P<0.10$ and $\mathrm{I}^{2}>50 \%$ indicated significant heterogeneity. The inverse variance method with a fixed-effects model was applied when heterogeneity was not found, whereas the random-effects model was used when heterogeneity was found. Publication bias was tested using funnel plots. $P<0.05$ was considered significant when measuring the effect sizes. This manuscript reporting adheres to PRISMA guidelines for reporting systematic reviews and meta-analyses.

\section{Results}

\section{Eligible studies}

The search for the aforementioned keywords allowed the identification of 4538 articles. Five RCTs [17-21] 
and six CCTs $[9,11,22-25]$ were considered eligible for this meta-analysis (Fig. 1). The analyses included 1240 patients who were in the PC group $(n=557)$ or in the AC group $(n=683)$. The detailed characteristics of the patients are listed in Table 1 and Additional file 1. Four RCTs scored 3 in the JCS, indicating that they were high-quality studies (Table 2). Three CCTs scored 6 (moderate-quality study) on the Newcastle-Ottawa scale and 3 CCTs scored 7 (high-quality study) (Table 3 ).

\section{Hazard ratio for the overall survival}

Nine $[9,17-22,24,25]$ out of eleven studies (5 RCTs and 4 CCTs) evaluated provided effective data for the calculation of the HR for OS. Compared with the AC group, the PC group had significantly better prognosis (HR, 0.74; $95 \%$ CI, 0.61 to $0.89 ; P<0.01$, Fig. 2a-c). The difference between the two groups remained significant subgroup analysis that only consisted of RCTs (HR, 0.74; $95 \% \mathrm{CI}, 0.60$ to $0.93 ; P=0.01$ ) (Fig. 2a).

We also performed a subgroup analysis examining the nine studies divided into two subgroups: the fluoropyrimidine monotherapy subgroup and combination chemotherapy subgroup (Fig. 2b). PC did not demonstrate improved prognosis in the fluoropyrimidine monotherapy subgroup (HR, 0.93; $95 \% \mathrm{CI}, 0.56$ to $1.55 ; P=0.84$ ) but did show improved prognosis in the combination chemotherapy subgroup (HR, 0.59; $95 \%$ CI, 0.46 to $0.76 ; P<0.01$ ).

We also performed a subgroup analysis considering the study locations (Fig. 2c). Five where Chinese studies and four Japanese studies. PC resulted in significantly better prognosis in the Chinese studies (HR, 0.61; $95 \%$ CI, 0.47 to $0.80 ; P<0.01$ ) but not in the Japanese studies (HR, 0.88; $95 \% \mathrm{CI}, 0.68$ to $1.13 ; P=0.30$ ).

\section{1-, 2-, 3-, 5-year survival rates}

Nine $[9,17-22,24,25]$, nine $[9,17-22,24,25]$, seven $[9,17,18,20-22,25]$, six $[9,18,20,21,23,25]$ studies reported 1-, 2-, 3-, 5- year survival rates, respectively. There were no significant differences in the 1- and 2year survival rates between the two study groups (1-year survival rate: RR, $0.81 ; 95 \% \mathrm{CI}, 0.60$ to $1.09 ; P=0.17$, Additional file 2A; 2-year survival rate: RR, 0.90; $95 \% \mathrm{CI}$, 0.77 to $1.04 ; P=0.15$, Additional file $2 \mathrm{~B}$ ). However, the PC group showed significantly better prognosis for 3- and 5year survival rates (3-year survival rate: RR, 0.80; $95 \% \mathrm{CI}$, 0.67 to $0.96 ; P=0.01$, Additional file $2 \mathrm{C}$; 5 -year survival rate: $\mathrm{RR}, 0.77 ; 95 \% \mathrm{CI}, 0.64$ to $0.92 ; P<0.01$, Additional file $2 \mathrm{D})$.

\section{Response rate to neoadjuvant chemotherapy}

Eight studies $[9,11,17-20,22,24]$ reported the response rates to NAC in 358 patients. The response rate ranged between 33.3 and $70.0 \%$. In total, 199 patients achieved CR or PR. The overall response rate was $55.6 \%$.

\section{Radical resection rate}

Seven studies [9, 11, 17-19, 22, 24] reported the radical resection rate. A total of 218 out of 265 patients (82\%) in the PC group and 218 out of 292 (74\%) patients in the AC group received radical resection. Although no significant difference was observed, the PC group showed a trend towards a higher radical resection rate (RR, 1.10; $95 \%$ CI, 0.96 to 1.27; $P=0.17$, Fig. 3a).

\section{Total post-operative complication rate}

Five studies $[9,11,19,22,24]$ reported the prevalence of complications. A total of 31 out of the 213 patients in the $\mathrm{PC}$ group and 37 out of 243 patients in the $\mathrm{AC}$ group suffered postoperative complications. There was

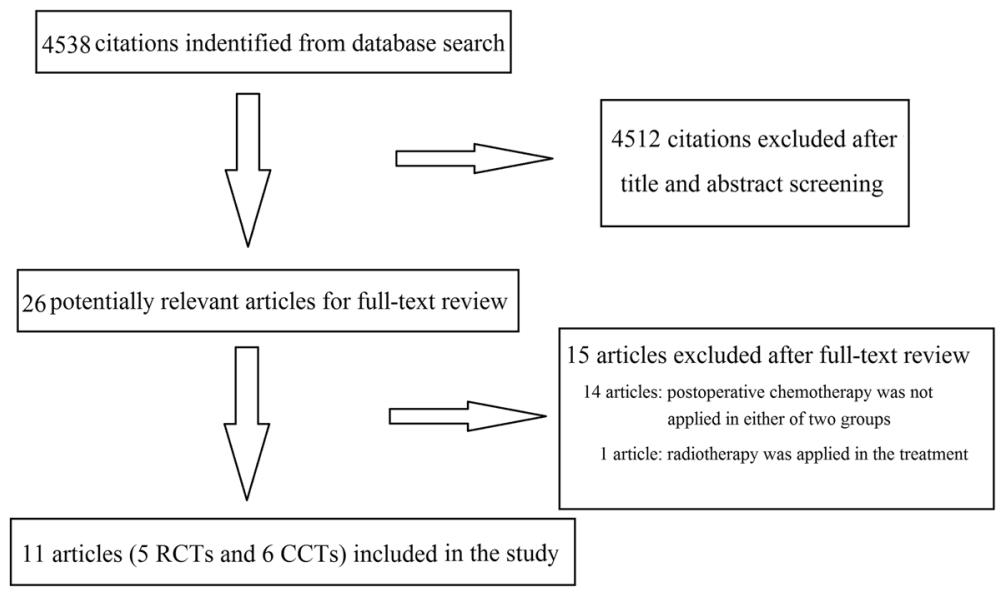

Fig. 1 Flow chart of articles selection 
Table 1 Main characteristics of including studies

\begin{tabular}{|c|c|c|c|c|c|c|c|c|c|c|c|c|c|}
\hline \multirow[t]{3}{*}{ study } & \multirow[t]{3}{*}{ year } & \multirow[t]{3}{*}{ place } & \multirow[t]{3}{*}{ design } & \multicolumn{2}{|c|}{ Patients number } & \multirow[t]{3}{*}{ follow-up } & \multicolumn{3}{|l|}{ Regimen $^{a}$} & \multicolumn{2}{|l|}{ Age } & \multicolumn{2}{|c|}{ Sex (male/female) } \\
\hline & & & & \multirow[t]{2}{*}{ PC } & \multirow[t]{2}{*}{$A C$} & & \multicolumn{2}{|l|}{ PC group } & \multirow[t]{2}{*}{ AC group } & \multirow[t]{2}{*}{$P C$} & \multirow[t]{2}{*}{$A C$} & \multirow[t]{2}{*}{ PC } & \multirow[t]{2}{*}{$\mathrm{NC}$} \\
\hline & & & & & & & preoperative & postoperative & & & & & \\
\hline Yonemura & 1993 & Japan & $\mathrm{RCT}$ & 29 & 26 & 3 years & PMUE & PMUE & PMUE & $61.4 \pm 8.34$ & $56.4 \pm 9.6$ & $21 / 8$ & $20 / 6$ \\
\hline Kobayashi & 2000 & Japan & $\mathrm{RCT}$ & 91 & 80 & 5 years & $5^{\prime}-D F U R$ & 5'-DFUR + MMC & 5'-DFUR + MMC & 57.8 & 60.2 & $65 / 26$ & $55 / 25$ \\
\hline $\mathrm{Nio}$ & 2004 & Japan & RCT & 102 & 193 & 7 years & UFT & UFT or FPEPIR + UFT & UFT or FPEPIR + UFT & $63.5 \pm 11.9$ & $65.3 \pm 11.5$ & $70 / 32$ & $141 / 52$ \\
\hline Qu & 2010 & China & RCT & 39 & 39 & $\geq 2$ years & PTX + FOLFOX4 & PTX + FOLFOX4 or ECF & PTX + FOLFOX4 & NA & NA & $26 / 13$ & $22 / 17$ \\
\hline X.Sun & 2011 & China & $\mathrm{RCT}$ & 29 & 26 & 3 years & DCF & DCF & DCF & $52.6(33-72)$ & & $37 / 18$ & \\
\hline Z.Sun & 2014 & China & CCT & 23 & 35 & 3 years & FOLFOX4 & FOLFOX & FOLFOX & $58(34-79)$ & $57(31-80)$ & $15 / 8$ & $22 / 13$ \\
\hline Feng & 2015 & China & CCT & 80 & 90 & Till discharge & SOX & SOX & SOX & $61(21-74)$ & $59(29-82)$ & $63 / 17$ & $71 / 19$ \\
\hline Li & 2012 & China & CCT & 33 & 37 & $\geq 5$ years & FOLFOX & FOLFOX & FOLFOX & $65(41-75)$ & $61(27-78)$ & $23 / 10$ & $30 / 7$ \\
\hline J.Zhang & 2012 & China & CCT & 38 & 42 & 5 years & mFOLFOX7 & mFOLFOX7 or mECF & mFOLFOX7 & NA & NA & $22 / 16$ & $26 / 16$ \\
\hline Nishioka & 1982 & Japan & CCT & 64 & 59 & 5 years & $5-\mathrm{FU}$ & 5-FU and MMP & 5-FU and MMP & NA & NA & NA & NA \\
\hline C.Zhang & 2004 & China & CCT & 29 & 56 & 5 years & FAP or FMP & FAP or FMP & FAP or FMP & $54.9 \pm 12.9$ & & $69 / 22$ & \\
\hline
\end{tabular}

$P C$ perioperative chemotherapy, $A C$ adjuvant chemotherapy, $R C T$ randomized controlled trails, $C C T$ clinical controlled trails

${ }^{a}$ concrete information of regimens is shown in Additional file 1 
Table 2 The risk of bias of RCTS (Jadad scale)

\begin{tabular}{llllll}
\hline Reference & Randomization & Blinding & $\begin{array}{l}\text { Withdraw } \\
\text { and dropout }\end{array}$ & $\begin{array}{l}\text { Jadad's } \\
\text { score }\end{array}$ & Quality \\
\hline Yonemura & 2 & 0 & 0 & 2 & Moderate \\
Kobayashi & 2 & 0 & 1 & 3 & High \\
Nio & 2 & 0 & 1 & 3 & High \\
Qu & 2 & 0 & 1 & 3 & High \\
X.Sun & 2 & 0 & 1 & 3 & High \\
\hline
\end{tabular}

Randomization: randomization was described with appropriate method- 2 score, randomization was described without appropriate method- 1 score, no randomization- 0 score

Blinding: blinding was performed on all doctors and patients- 2 score, blinding was partially performed on doctors and patients- 1 score, no blinding- 0 score Withdraw and dropout: the reason of withdraw and dropout was described- 1 score, the reason of withdraw and dropout was not described- 0 score Quality: High-quality trials should score $\geq 3$. moderate-quality trials should score $\geq 2$

no significant difference between two groups (RR, 0.98; $95 \%$ CI, 0.63 to $1.51 ; P=0.91$, Fig. $3 b)$.

\section{Adverse effects of chemotherapy}

Three studies [17, 19, 24] reported adverse effects of chemotherapy in detail. Our meta-analysis indicated that all the adverse effects (including nausea and vomit, gastrointestinal problem, liver toxicity, neurologic effects, leukopenia, thrombocytopenia, and neutropenia) were not significantly different between the two study groups $(P>0.05$ for all the comparisons, Additional file 3).

\section{Publication bias}

A funnel-plot analysis was performed to determine the publication bias on the basis of the measurement of HR for OS (Fig. 4). The analysis indicated that all the studies were within the funnel plot and were distributed symmetrically.

\section{Discussion}

Two methods of chemotherapy delivery, perioperative chemotherapy (PC) and adjuvant chemotherapy (AC) are widely used. However, there is no high level evidence comparing the prognosis and safety between PC and AC. Our meta-analysis that synthesized the results of several smaller studies showed that PC was superior to $\mathrm{AC}$ when considering the HR for OS and the 3-, 5-year survival rates. This result indicates that the addition of chemotherapy prior to surgery could provide additional benefits over chemotherapy provided after surgery alone. This may occur because of the effects of NAC in reducing tumor burden and eradicating micrometastatic foci [8]. In this meta-analysis, the response rate to NAC reached $55.6 \%$. In addition, the radical resection rate was relatively higher in the $\mathrm{PC}$ group.

Fluoropyrimidine is the most common and widely accepted chemotherapy drug for GC [26, 27]. However, combination chemotherapy that includes fluoropyrimidine rather than fluoropyrimidine alone is used and recommended by most professionals [4, 28-31]. In our meta-analysis, PC failed to show significant benefits compared with $\mathrm{AC}$ in the fluoropyrimidine monotherapy subgroup. However, a significant difference was observed between the two groups in the combination chemotherapy subgroup. This suggests that combination chemotherapy is a better option for NAC in GC and provides significant advantage in relation to fluoropyrimidine monotherapy.

The stage of cancer is another important issue when choosing the treatment method. In the NCCN guideline, for early-stage GC, PC is not routinely recommended [6]. To better understand this issue, we considered the tumor stages reported in the studies included in this meta-analysis. In addition, in almost all the studies included, the majority, if not all, of the patients were at advanced stages. However, the RCT by Nio et al. [20] was an exception. Of the 295 patients evaluated in the RCT, 170 patients were stage 1, and this subgroup failed to show any advantage of $\mathrm{PC}$ over AC. On the other hand, when we redid the metaanalysis excluding stage 1 patients and only including stage 2 and 3 patients, the survival benefits of PC became more significant (HR 0.68; $95 \% \mathrm{CI}, 0.56$ to 0.83 ;

Table 3 The risk of bias of CCTS (NOS)

\begin{tabular}{|c|c|c|c|c|c|c|c|c|c|c|c|}
\hline \multirow[t]{2}{*}{ Reference } & \multicolumn{4}{|c|}{ Selection } & \multicolumn{2}{|c|}{ Comparability } & \multicolumn{3}{|c|}{ Outcome } & \multirow[t]{2}{*}{ Total } & \multirow[t]{2}{*}{ Quality } \\
\hline & REC & SNEC & $\mathrm{AE}$ & $\mathrm{DO}$ & SC & AF & $\mathrm{AO}$ & FU & FUO & & \\
\hline C.Zhang & 1 & 0 & 1 & 1 & 0 & 0 & 1 & 1 & 1 & 6 & Moderate \\
\hline Z.Sun & 1 & 1 & 1 & 1 & 0 & 0 & 1 & 1 & 1 & 7 & High \\
\hline Feng & 1 & 1 & 1 & 1 & 0 & 0 & 1 & 0 & 1 & 6 & Moderate \\
\hline $\mathrm{Li}$ & 1 & 1 & 1 & 1 & 0 & 0 & 1 & 0 & 1 & 6 & Moderate \\
\hline J.Zhang & 1 & 1 & 1 & 1 & 0 & 0 & 1 & 1 & 1 & 7 & High \\
\hline Nishioka & 1 & 1 & 1 & 1 & 0 & 0 & 1 & 1 & 1 & 7 & High \\
\hline
\end{tabular}

REC representativeness of the exposed cohort, SNEC selection of the non-exposed cohort, $A E$ ascertainment of exposure, DO demonstration that outcome of interest was not present at start of study, SC study controls for age, sex, $A F$ study controls for any additional factors, $A O$ assessment of outcome, $F U$ follow-up long enough for outcomes to occur, FUO adequacy of follow-up of cohorts 

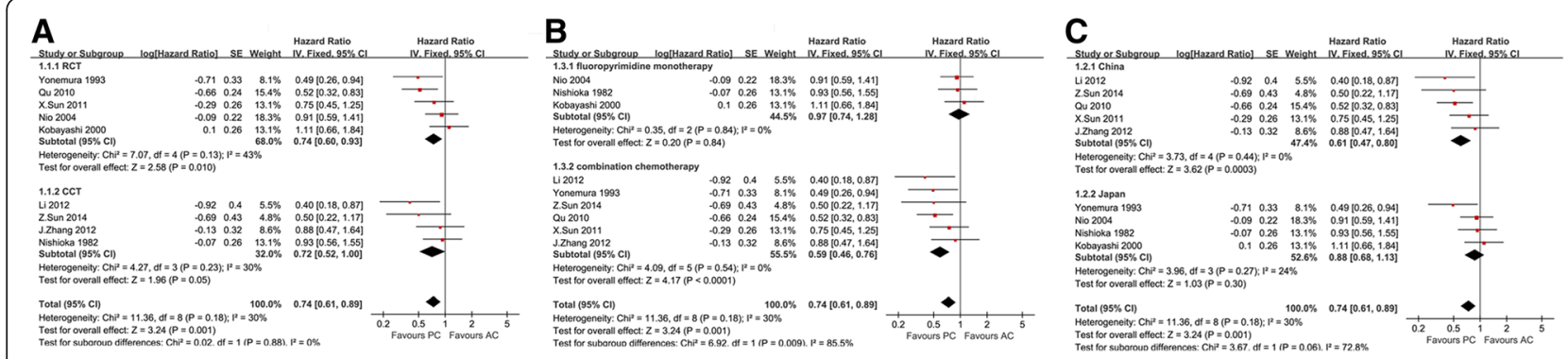

Fig. 2 a-c Meta-analysis of hazard ratio for overall survival subgrouped by (a) RCT or CCT, b neoadjuvant chemotherapy regimen, (c) where the study from

$P<0.01)$. Therefore, the conclusion that "perioperative chemotherapy was superior to adjuvant chemotherapy in the survival benefits" seems to be more suitable for advanced GC.

The results of two large European RCTs [4, 32], which compared PC and surgery alone, established PC as another alternative option for GC. However, no European studies have compared PC and AC. Furthermore, all 11 studies included in this meta-analysis were from Asian countries (China and Japan). We performed a subgroup analysis for these two countries and the results indicated that the Chinese group showed an advantage compared with the Japanese group. This observation may be explained by the fact that Nio et al. [20] included many early-stage patients and most Japanese studies used fluoropyrimidine monotherapy as their NAC method. This suggests that Japanese groups should give more consideration to the use of combination chemotherapy, especially in the pre-operative setting.

Another potential advantage of perioperative chemotherapy is that it increases the likelihood that patients will receive at least part of their planned systemic chemotherapy regimen. For example, Yonemura [17] reported that patients in PC group received relative more courses of regimen in fact. In that study, patients in PC and $\mathrm{AC}$ received an average of 2.9 and 2.3 courses of regimen respectively. However, this issue is not reported by the others studies. We believe that studies should pay more attention to this matter in the future.

Safety is always of the utmost concern in clinical practice. Because fibrosis, tissue edema and toxicity may result from chemotherapy $[11,33]$, there is a concern that the addition of chemotherapy prior to surgery may increase the risk during surgery as well as increase complication rates and adverse effects [34]. In our study, the complication rates and adverse effects during PC were similar to those of AC. Postoperative complication rates were also consistent with the studies that evaluated the effects of NAC (without the restrictions of AC administration) $[35,36]$. However, only three studies reported adverse effects, and these studies were not enough to draw a solid conclusion. More investigations are needed to evaluate the side effects of PC.

To the best of our knowledge, this is the first metaanalysis that compares $\mathrm{PC}$ with $\mathrm{AC}$ in GC. In our meta-analysis, we included 11 studies, five of which were RCTs, and found that PC was superior to AC in the survival effects without compromising safety. In addition, combination chemotherapy was a better option in the pre-operative setting over monotherapy. A subgroup analysis involving three studies [10] in a previous meta-analysis evaluated the effects of NAC in GC and found similar survival benefits. Several limitations of our study should be considered. First, we included

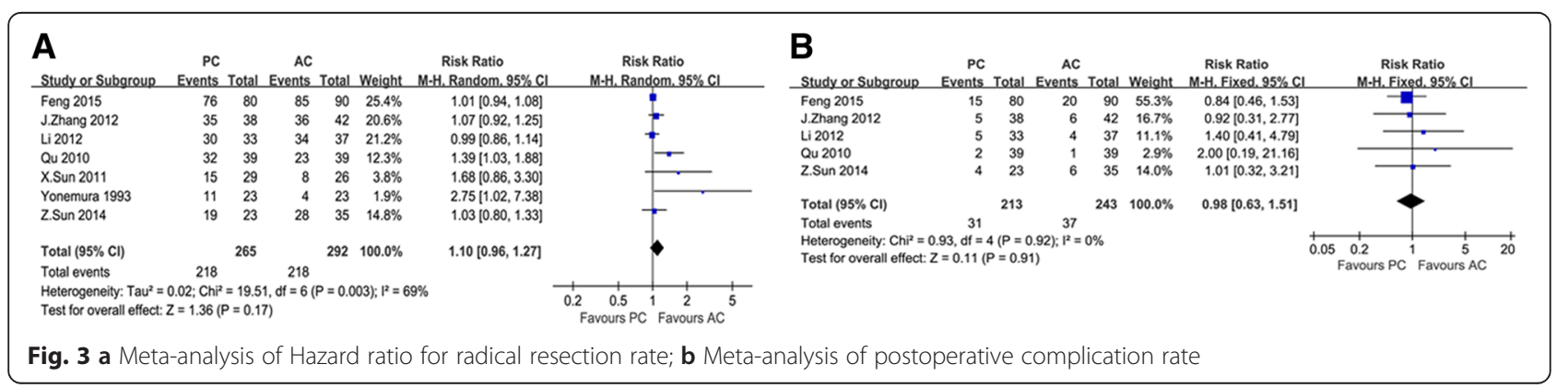




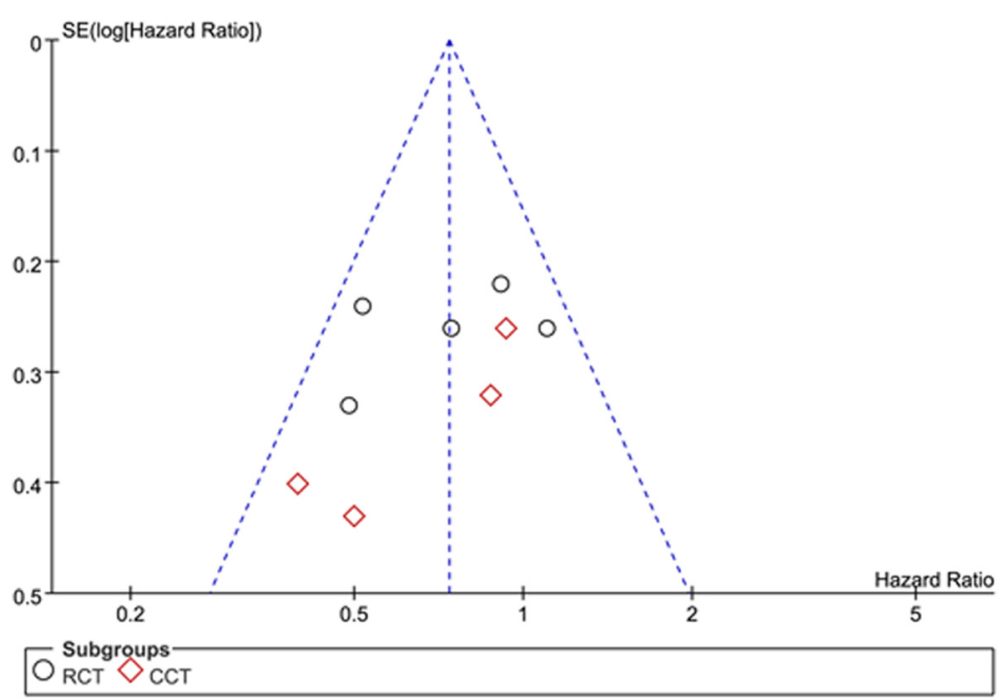

Fig. 4 Funnel plot of the studies on hazard ratio for overall survival

some retrospective studies, which may influence the statistical power. Second, all studies were from Asia and limits its generalizability for GC patients worldwide. Third, only a few studies compared the adverse effects of chemotherapy, which did not allow us to draw conclusions about the safety of PC.

\section{Conclusion}

Perioperative chemotherapy provides a survival advantage over adjuvant chemotherapy for GC patients, especially for the patients with advanced GC. In addition, combination chemotherapy is a better option for neoadjuvant chemotherapy regimen over monotherapy.

\section{Additional files}

Additional file 1: Concrete chemotherapy regimens used in included studies. (DOCX $22 \mathrm{~kb})$

Additional file 2: (A) Meta-analysis of 1 year survival rate; (B) Meta-analysis of 2 year survival rate; (C) Meta-analysis of 3 year survival rate; (D) Meta-analysis of 5 year survival rate. (TIF $457 \mathrm{~kb}$ )

Additional file 3: meta-analysis of chemotherapy adverse effects. (A) Nausea and vomit, (B) gastrointestinal problem, (C) liver toxicity, (D) neurologic effects, (E) leukopenia, (F) thrombocytopenia, $(G)$ neutropenia. (TIF 507 kb)

\section{Acknowledgments}

We thank the department of Surgical Oncology of First Hospital of China Medical University and the College of China Medical University for technical assistance.

\section{Funding}

This work was supported by Natural Science Foundation of Liaoning Province (No. 2014029201), Program of Education Department of Liaoning Province (L2014307), the Key Laboratory Programme of Education Department of Liaoning Province (LZ2015076).
Availability of data and materials

The datasets supporting the conclusions of this article are included within the article and its additional files.

\section{Authors' contributions}

JZ and PG contributed equally to this work. ZW participated in the conception and design of the study and coordination; JZ and XC participated in design of the study, data extraction, article selection and manuscript preparation and interpreted the results in collaboration with BM and YS; YY and JS participated in data extraction, article selection and data extraction; PG performed the statistical analysis and participated in the critical revision of the manuscript All authors drafted and critically revised the manuscript and approved the final version.

\section{Competing interests}

All the authors declare that they have no competing interests. And our manuscript has not been published previously and is not under consideration by any other publications.

\section{Consent for publication}

Not applicable.

Ethics approval and consent to participate

Not applicable.

Received: 25 May 2016 Accepted: 2 August 2016

Published online: 12 August 2016

\section{References}

1. Jemal A, Bray F, Center MM, Ferlay J, Ward E, Forman D. Global cancer statistics. CA Cancer J Clin. 2011;61(2):69-90

2. Herszenyi L, Tulassay Z. Epidemiology of gastrointestinal and liver tumors. Eur Rev Med Pharmacol Sci. 2010;14(4):249-58.

3. Sant M, Allemani C, Santaquilani M, Knijn A, Marchesi F, Capocaccia R, Group EW. EUROCARE-4. Survival of cancer patients diagnosed in 1995-1999. Results and commentary. Eur J Cancer. 2009;45(6):931-91.

4. Cunningham D, Allum WH, Stenning SP, Thompson JN, Van de Velde CJ, Nicolson M, Scarffe JH, Lofts FJ, Falk SJ, Iveson TJ, et al. Perioperative chemotherapy versus surgery alone for resectable gastroesophageal cancer. N Engl J Med. 2006;355(1):11-20.

5. Bang YJ, Kim YW, Yang HK, Chung HC, Park YK, Lee KH, Lee KW, Kim YH, Noh SI, Cho JY, et al. Adjuvant capecitabine and oxaliplatin for gastric cancer after D2 gastrectomy (CLASSIC): a phase 3 open-label, randomised controlled trial. Lancet. 2012;379(9813):315-21. 
6. Ajani JA, D'Amico TA, Almhanna K, Bentrem DJ, Besh S, Chao J, Das P, Denlinger C, Fanta P, Fuchs CS et al.: NCCN Clinical Practice Guidelines in Oncology: Gastric cancer. Version 1, 2016. http://www.nccn.org/ professionals/physician_gls/f_guidelines.asp

7. Frei 3rd E. Clinical cancer research: an embattled species. Cancer. 1982; 50(10):1979-92.

8. Frei 3rd E, Miller D, Clark JR, Fallon BG, Ervin TJ. Clinical and scientific considerations in preoperative (neoadjuvant) chemotherapy. Recent Results Cancer Res. 1986;103:1-5.

9. Li ZY, Koh CE, Bu ZD, Wu AW, Zhang LH, Wu XJ, Wu Q, Zong XL, Ren H, Tang L, et al. Neoadjuvant chemotherapy with FOLFOX: improved outcomes in Chinese patients with locally advanced gastric cancer. J Surg Oncol. 2012;105(8):793-9.

10. Yang $Y$, Yin X, Sheng L, Xu S, Dong L, Liu L. Perioperative chemotherapy more of a benefit for overall survival than adjuvant chemotherapy for operable gastric cancer: an updated Meta-analysis. Sci Reports. 2015;5:12850.

11. Feng $D$, Leong M, Li T, Chen L, Li T. Surgical outcomes in patients with locally advanced gastric cancer treated with S-1 and oxaliplatin as neoadjuvant chemotherapy. World J Surg Oncol. 2015;13:11.

12. Fujiwara Y, Takiguchi S, Nakajima K, Miyata H, Yamasaki M, Kurokawa Y, Okada K, Mori M, Doki Y. Neoadjuvant intraperitoneal and systemic chemotherapy for gastric cancer patients with peritoneal dissemination. Ann Surg Oncol. 2011;18(13):3726-31.

13. Macdonald JS, Smalley SR, Benedetti J, Hundahl SA, Estes NC, Stemmermann GN, Haller DG, Ajani JA, Gunderson LL, Jessup JM, et al. Chemoradiotherapy after surgery compared with surgery alone for adenocarcinoma of the stomach or gastroesophageal junction. N Engl J Med. 2001;345(10):725-30.

14. Grobmyer SR, Pieracci FM, Allen PJ, Brennan MF, Jaques DP. Defining morbidity after pancreaticoduodenectomy: use of a prospective complication grading system. J Am Coll Surg. 2007;204(3):356-64.

15. Stang A. Critical evaluation of the Newcastle-Ottawa scale for the assessment of the quality of nonrandomized studies in meta-analyses. Eur J Epidemiol. 2010;25(9):603-5.

16. Tierney JF, Stewart LA, Ghersi D, Burdett S, Sydes MR. Practical methods for incorporating summary time-to-event data into meta-analysis. Trials. 2007;8:16.

17. Yonemura Y, Sawa T, Kinoshita K, Matsuki N, Fushida S, Tanaka S, Ohoyama S, Takashima T, Kimura H, Kamata T, et al. Neoadjuvant chemotherapy for high-grade advanced gastric cancer. World J Surg. 1993;17(2):256-61. discussion 261-252.

18. Sun XC, Lin J, Ju AH. Treatment of Borrmann type IV gastric cancer with a neoadjuvant chemotherapy combination of docetaxel, cisplatin and 5-fluorouracil/leucovorin. J Int Med Res. 2011;39(6):2096-102.

19. Qu JJ, Shi YR, Liu FR, Ma SQ, Ma FY. A clinical study of paclitaxel combined with FOLFOX4 regimen as neoadjuvant chemotherapy for advanced gastric cancer. Chin J Gastrointestinal Surg. 2010;13(9):664-7.

20. Nio Y, Koike M, Omori H, Hashimoto K, Itakura M, Yano S, Higami T, Maruyama R. A randomized consent design trial of neoadjuvant chemotherapy with tegafur plus uracil (UFT) for gastric cancer-a single institute study. Anticancer Res. 2004;24(3b):1879-87.

21. Kobayashi T, Kimura T. Long-term outcome of preoperative chemotherapy with 5'-deoxy-5-fluorouridine (5'-DFUR) for gastric cancer. Gan Kagaku ryoho Cancer Chemotherapy. 2000;27(10):1521-6.

22. Zhang J, Chen RX, Zhang J, Cai J, Meng H, Wu GC, Zhang ZT, Wang Y, Wang KL. Efficacy and safety of neoadjuvant chemotherapy with modified FOLFOX7 regimen on the treatment of advanced gastric cancer. Chin Med J. 2012;125(12):2144-50.

23. Zhang CW, Zou SC, Shi D, Zhao DJ. Clinical significance of preoperative regional intra-arterial infusion chemotherapy for advanced gastric cancer. World J Gastroenterol. 2004;10(20):3070-2.

24. Sun Z, Zhu RJ, Yang GF, Li Y. Neoadjuvant chemotherapy with FOLFOX4 regimen to treat advanced gastric cancer improves survival without increasing adverse events: a retrospective cohort study from a Chinese center. Sci World J. 2014:2014:418694.

25. Nishioka B, Ouchi T, Watanabe S, Umehara M, Yamane E, Yahata K, Muto F, Kojima O, Nomiyama S, Sakita M, et al. Follow-up study of preoperative ora administration of an antineoplastic agent as an adjuvant chemotherapy in stomach cancer. Gan Kagaku ryoho Cancer Chemotherapy. 1982;9(8):1427-32.

26. Fukushima M, Satake H, Uchida J, Shimamoto Y, Kato T, Takechi T, Okabe H, Fujioka A, Nakano K, Ohshimo H, et al. Preclinical antitumor efficacy of S-1: a new oral formulation of 5-fluorouracil on human tumor xenografts. Int J Oncol. 1998:13(4):693-8.

27. Schoffski P. The modulated oral fluoropyrimidine prodrug S-1, and its use in gastrointestinal cancer and other solid tumors. Anti-Cancer Drugs. 2004 15(2):85-106.

28. Mackenzie M, Spithoff $K$, Jonker D. Systemic therapy for advanced gastric cancer: a clinical practice guideline. Curr Oncol. 2011;18(4):e202-9.

29. lacovelli R, Pietrantonio F, Maggi C, de Braud F, Di Bartolomeo M. Combination or single-agent chemotherapy as adjuvant treatment of gastric cancer: A systematic review and meta-analysis of published trials. Crit Rev Oncol/Hematol. 2015:98:24-8.

30. Koizumi W, Narahara H, Hara T, Takagane A, Akiya T, Takagi M, Miyashita K, Nishizaki T, Kobayashi O, Takiyama W, et al. S-1 plus cisplatin versus S-1 alone for first-line treatment of advanced gastric cancer (SPIRITS trial): a phase III trial. Lancet Oncol. 2008:9(3):215-21.

31. Ajani JA, Moiseyenko VM, Tjulandin S, Majlis A, Constenla M, Boni C, Rodrigues A, Fodor M, Chao Y, Voznyi E, et al. Clinical benefit with docetaxel plus fluorouracil and cisplatin compared with cisplatin and fluorouracil in a phase III trial of advanced gastric or gastroesophageal cancer adenocarcinoma: the V-325 Study Group. J Clin Oncol. 2007;25(22):3205-9.

32. Ychou M, Boige V, Pignon JP, Conroy T, Bouche O, Lebreton G, Ducourtieux M, Bedenne L, Fabre JM, Saint-Aubert B, et al. Perioperative chemotherapy compared with surgery alone for resectable gastroesophageal adenocarcinoma: an FNCLCC and FFCD multicenter phase III trial. J Clin Oncol. $2011 ; 29(13): 1715-21$.

33. Friedman MA, Ogawa M, Carter SK, Sakurai Y, Kimura K, Hannigan J. Chemotherapy of disseminated gastric cancer. A joint effort of the Northern California Oncology Group and the Japanese Gastric Cancer Chemotherapy Group. Cancer. 1983;52(10):1771-7.

34. Xu AM, Huang L, Liu W, Gao S, Han WX, Wei ZJ. Neoadjuvant chemotherapy followed by surgery versus surgery alone for gastric carcinoma: systematic review and meta-analysis of randomized controlled trials. PLoS One. 2014;9(1):e86941.

35. Xiong $\mathrm{BH}$, Cheng $Y, M a L$, Zhang $C Q$. An updated meta-analysis of randomized controlled trial assessing the effect of neoadjuvant chemotherapy in advanced gastric cancer. Cancer Investig. 2014;32(6):272-84.

36. Li W, Qin J, Sun YH, Liu TS. Neoadjuvant chemotherapy for advanced gastric cancer: a meta-analysis. World J Gastroenterol. 2010;16(44):5621-8.

\section{Submit your next manuscript to BioMed Central and we will help you at every step:}

- We accept pre-submission inquiries

- Our selector tool helps you to find the most relevant journal

- We provide round the clock customer support

- Convenient online submission

- Thorough peer review

- Inclusion in PubMed and all major indexing services

- Maximum visibility for your research

Submit your manuscript at www.biomedcentral.com/submit
Biomed Central 